\title{
Numerical Investigation on Stress Concentration of Tension Steel Bars with One or Two Corrosion Pits
}

\author{
Jian Hou' ${ }^{1}$ and Li Song ${ }^{2}$ \\ ${ }^{1}$ Department of Civil Engineering, Xian Jiaotong University, Xian 710049, China \\ ${ }^{2}$ School of Civil Engineering, Central South University, 22 Shaoshan South Road, Changsha 410075, China
}

Correspondence should be addressed to Li Song; songlisong2002@126.com

Received 1 April 2015; Accepted 10 August 2015

Academic Editor: Ana S. Guimarães

Copyright (c) 2015 J. Hou and L. Song. This is an open access article distributed under the Creative Commons Attribution License, which permits unrestricted use, distribution, and reproduction in any medium, provided the original work is properly cited.

Pitting corrosion has been observed in steel bars of existing reinforced concrete (RC) structures in different erosion environments and has been identified as a potential origin for fatigue crack nucleation. In the present study, under uniaxial tension loading, stress distribution in the steel bars with one or two semiellipsoidal corrosion pits has systematically been investigated by conducting a series of three-dimensional semiellipsoidal pitted models. Based on the finite element analyses, it is shown that stress concentration factor (SCF) increases linearly with increasing pit aspect ratio $(a / b)$ and increases nonlinearly with increasing pit relative depth $(a / R)$ for single corrosion pit problem. For double corrosion pits problem, the SCF decreases nonlinearly with increasing angle of two transverse pits $(\theta)$. The interaction of two longitudinal pits can be ignored in the calculation of SCF even if the distance of two pits $(d)$ is very small.

\section{Introduction}

Steel reinforcement in RC structures is generally protected by a passive film formed in the alkaline environment due to the hydration products of cement $[1,2]$. However, the protective film can be destroyed by attack of aggressive ions such as chloride and carbon dioxide [3]. Due to varying external environments, nonhomogeneous properties of both concrete cover and passive film, and metallurgical and compositional nonuniformity of steel, corrosion in applications is often observed to be nonuniformly distributed along the length of a steel bar. Pitting corrosion is a localized form of corrosion by which cavities or holes are produced in the material. Corrosion pits, acting as geometric discontinuities, lead to stress concentration and facilitate fatigue crack initiation and propagation [4-6]. A small, narrow pit with minimal overall steel loss can lead to the failure of an entire RC structure. Consequently, pitting is considered to be more dangerous than uniform corrosion damage.

Understanding and predicting the effect of corrosion pits on mechanical properties of corroded steel bars is very important for the integrity and safety of existing RC structure in erosion environments. Some tensile tests have been conducted to characterize the reduction of the mechanical properties of corroded steel bars $[7,8]$. However, these studies used the average corrosion loss without considering the nonuniform distribution of corrosion pits. Tang et al. [9] detected the nonuniform distribution of corrosion pits using the 3D laser scanner and experimentally investigated the effect of corrosion nonuniformity on the mechanical property degradation of deformed steel bars. But these studies only investigated the macromechanical properties such as yield strength, ultimate strength, and elongation, without considering the nonuniform distribution of stress around corrosion pits before steel bars fracture, which is important for fatigue failure of steel bars. Cerit [10] numerically investigated the stress concentration factor (SCF) at the corrosion pit of tension circular cross section shaft, in which the shape of corrosion pit was simplified as semiellipsoid. Although there are some experimental and numerical works on the effect of corrosion pits on mechanical properties of corroded steel bars, few or no three-dimensional (3D) and systematic studies, which cover different aspect ratios and two interacting corrosion pits on estimation of SCF, have been cited in the literature. 


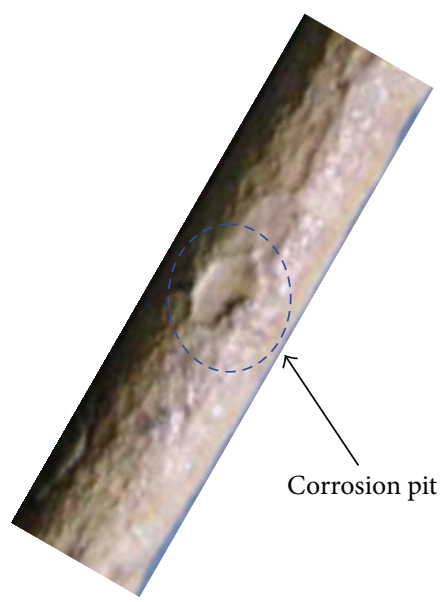

(a)

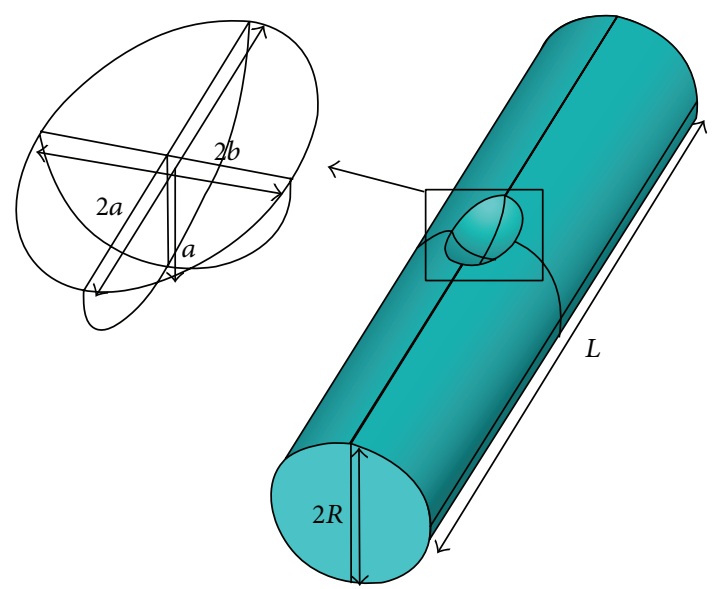

(b)
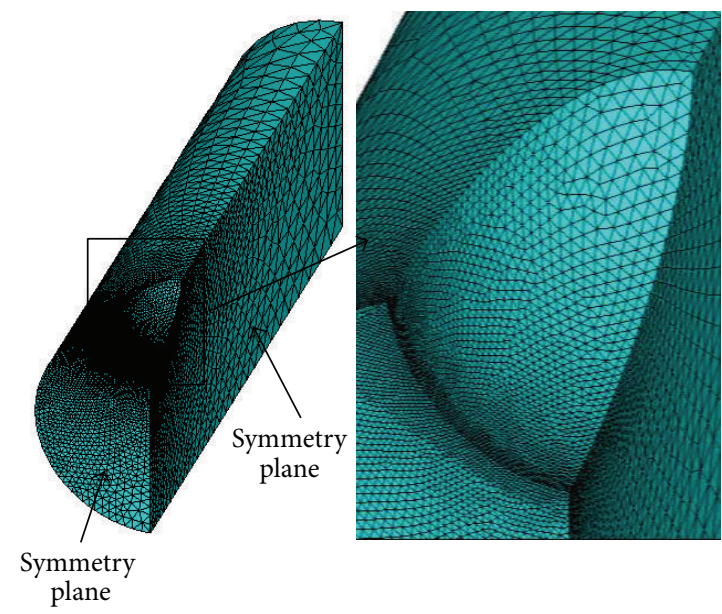

(c)

FIGURE 1: Illustration of single pit problem: (a) photo of corrosion pit; (b) geometric configuration of steel bar and corrosion pit; (c) finite element model.

In the present study, the stress concentration effect of single semiellipsoidal corrosion pits with various aspect ratios and pit depths has systematically been investigated for uniaxial tension loading by conducting a series of $3 \mathrm{D}$ stress analyses. Also, the contribution of two interacting corrosion pits to value of SCF has been examined for various angles in transverse direction and distances in longitudinal direction.

\section{Finite Element Model}

In the computations, the shape of corrosion pits is ideally simplified as semiellipsoid, which is also adopted in the literatures $[10,11]$. The length $(L)$ and radius $(R)$ of steel bars are, respectively, $100 \mathrm{~mm}$ and $10 \mathrm{~mm}$. A linear elastic model was used, and modulus of elasticity and Poisson's ratio are taken as $200 \mathrm{GPa}$ and 0.3 , respectively. SCF is calculated by using the ratio of maximum tension stress to nominal tension stress. Since the cross-sectional area of pit is very small compared with that of the steel bar, it is neglected in the calculation of the nominal tension stress. A uniform stress of
$100 \mathrm{MPa}$ is applied on the end of steel bar. For single corrosion pit problem (see Figure 1(b)), the longitudinal radius of pit (b) is varied from $10 \mathrm{~mm}$ to $0.2 \mathrm{~mm}$ while the transverse radius and pit depth $(a)$ are set to be $2 \mathrm{~mm}$, corresponding to the value of pit aspect ratio $(a / b)$ from 0.2 to 10 . Also, the pit depth is varied from $0.5 \mathrm{~mm}$ to $5 \mathrm{~mm}$ while the value of $a / b$ is set to be 0.5 , corresponding to the value of pit relative depth $(a / R)$ from 0.05 to 0.5 . For two transverse pits' problem (see Figure 2(a)), the angle of two pits $(\theta)$ is varied from $25^{\circ}$ to $60^{\circ}$ while the values of $a$ and $b$ are set to be $2 \mathrm{~mm}$ and $4 \mathrm{~mm}$, respectively. For two longitudinal pits' problem (see Figure $3(\mathrm{a})$ ), the distance of two pits $(d)$ is varied while the values of $a$ and $b$ are set to be $2 \mathrm{~mm}$ and $4 \mathrm{~mm}$, respectively.

All analyses are carried out using the software ANSYS. Owing to the symmetry, only quarter of each steel bar is modeled, as shown in Figures 1(c), 2(b), and 3(b). Appropriate boundary constraints are placed in all planes of symmetry. To accommodate the variations of the stress field quantities near the pit, the size of the element decreases gradually with decreasing distance from the pit. A mesh convergence study has been carried out to ensure that the SCF in the pit 


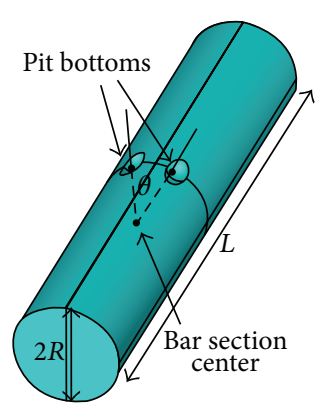

(a)

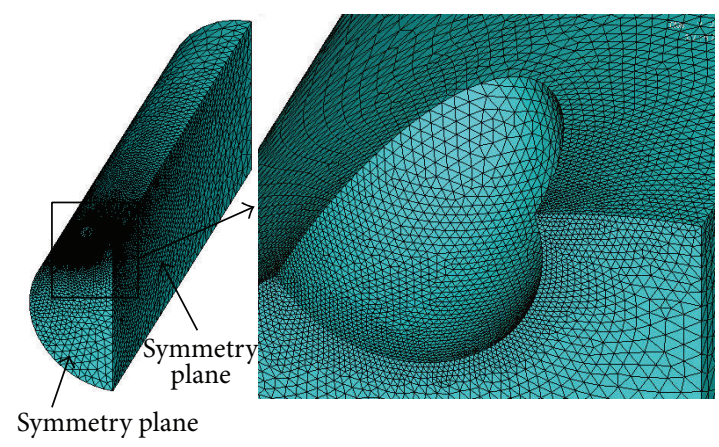

(b)

FIGURE 2: Illustration of two transverse pits' problem: (a) geometric configuration of steel bar and corrosion pit; (b) finite element model.

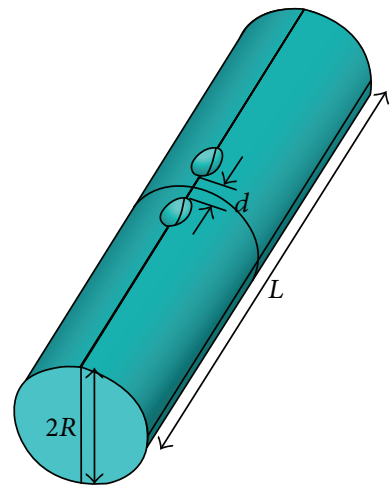

(a)

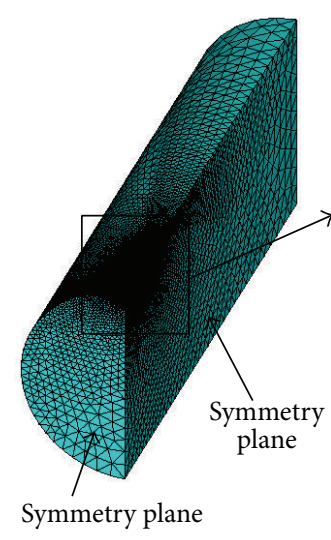

(b)

FIGURE 3: Illustration of two longitudinal pits' problem: (a) geometric configuration of steel bar and corrosion pit; (b) finite element model.

region is convergent; the SCF for various mesh numbers is shown in Figure 4. In the present study, the simulation model for steel bar with single pit $(a=2 \mathrm{~mm}, b=1 \mathrm{~mm})$ is constructed nearly by 270000 elements. For 3D numerical analyses, uniform shapes and forms of elements play an important role in the sensitivity of the results. When the pit dimensions and number are changed, the mesh density around the pit is altered to ensure consistency in the size of the elements created around each pit, as shown in Figures 1(c), 2(b), and 3(b).

\section{Single Corrosion Pit Problem}

3.1. The Distributions of Stress with Various Pit Aspect Ratios $(a / b)$. Figure 5 shows the stress distributions with $a / b=0.2$ and $a / b=3.33$. From the stress contour, it can be seen that the stress concentration zone is near the pit, which narrows gradually with increasing value of $a / b$. The maximum stress region is near the intermediate cross section of pit in tension direction. The maximum stress occurs at the cross points of the surface of steel bar and the intermediate cross section of pit, and the minimum stress occurs at the ends of the pit in tension direction. The SCF values versus $a / b$ for $a=2 \mathrm{~mm}$ are shown in Figure 6. It is obvious that the SCF values linearly increase with increasing $a / b$. The SCF values are 1.164 and 12.41 for $a / b=0.2$ and $a / b=10$, respectively.

3.2. The Distributions of Stress with Various Pit Relative Depths $(a / R)$. The stress distributions with $a / R=0.05$ and $a / R=$ 0.5 are given in Figure 7. From the stress contour, it is shown that the stress concentration zone becomes proportionally larger with increasing value of $a / R$. The overall shape of stress contour is similar for different $a / R$. But the relative size of maximum stress region narrows slightly with increasing value of $a / R$. The variations of SCF with $a / R$ for $a / b=0.5$ are shown in Figure 8 (calculated value). The SCF values increase nonlinearly with increasing $a / R$, and they are 1.452 and 1.727 for $a / R=0.05$ and $a / R=0.5$, respectively.

Actually, the tension area of steel bar at pit root decreases gradually with increasing $a / R$ for given $R$. So the SCF values should increase gradually with increasing $a / R$ even if the stress distributions are absolutely similar for different $a / R$. Considering only the decrease of tension area of steel bar with increasing $a / R$, the corrected SCF values (see Figure 8) can be obtained based on the SCF value for $a / R=0.05$. It can be seen that the corrected values are smaller than the calculated 


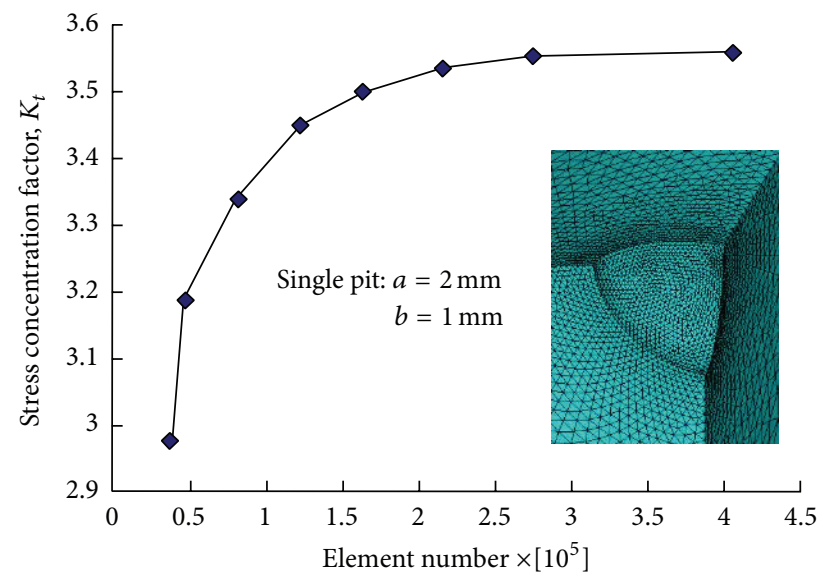

Figure 4: Variations of stress concentration factor with element number.

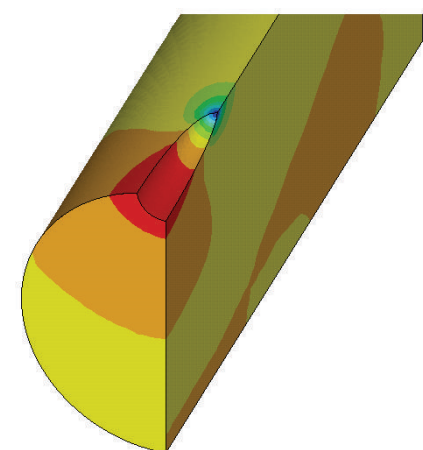

Min 43.8

$\operatorname{Max} 116.4$
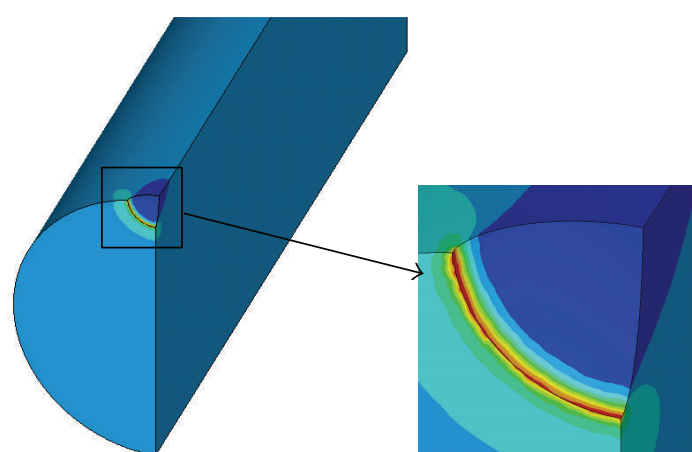

Min -3.6

$\operatorname{Max} 515.7$

(a)

(b)

FIGURE 5: Stress distributions near the pit with various aspect ratios: (a) $a / b=0.2$, (b) $a / b=3.33$.

values, which indicates that the stress distributions become more uneven with increasing $a / R$. The conclusion conforms with the stress distributions in Figure 7.

\section{Double Corrosion Pits Problem}

4.1. The Interaction of Two Transverse Pits. The stress distributions with $\theta=25^{\circ}, \theta=35^{\circ}$, and $\theta=60^{\circ}$ are given in Figure 9. From the stress contour, it can be found that the maximum stress region lies between two pits when $\theta$ is smaller. With the increase of the angle of two pits, the maximum stress region is gradually away from the symmetry plane between two pits. When $\theta=60^{\circ}$, it is obvious that the maximum stress region is near the intermediate cross section of each pit in tension direction and the overall stress distribution near the pits is similar to that of single corrosion pit problem. When $\theta$ is smaller, the maximum stress occurs at the cross points near symmetry plane of the surface of steel bar and the intermediate cross section of each pit. But when $\theta$ is big enough, the maximum stress occurs at the cross points away from symmetry plane of the surface of steel bar and the intermediate cross section of each pit. The variations of SCF values with $\theta$ for $a=2 \mathrm{~mm}$ and $b=4 \mathrm{~mm}$ are shown in Figure 10. The SCF values decrease nonlinearly with increasing $\theta$, and they are 2.437 and 1.512 for $\theta=25^{\circ}$ and $\theta=60^{\circ}$, respectively. It can be noted that the SCF value approaches gradually 1.508 of single pit problem with increasing $\theta$. The above analysis shows that the interaction of two transverse corrosion pits decreases gradually with increasing angle of two pits.

4.2. The Interaction of Two Longitudinal Pits. The stress distribution with $d=1 \mathrm{~mm}$ is given in Figure 11. From the stress contour, it can be seen that the region between two corrosion pits is the minimum stress region. The maximum stress region is near the intermediate cross section of each pit in tension direction and is far away from the symmetry plane between two corrosion pits. The maximum stress occurs at the cross points of the surface of steel bar and the intermediate cross section of each pit. So the influence of interaction of two longitudinal pits on the SCF is very small. Because the region between two corrosion pits is the minimum stress region, 


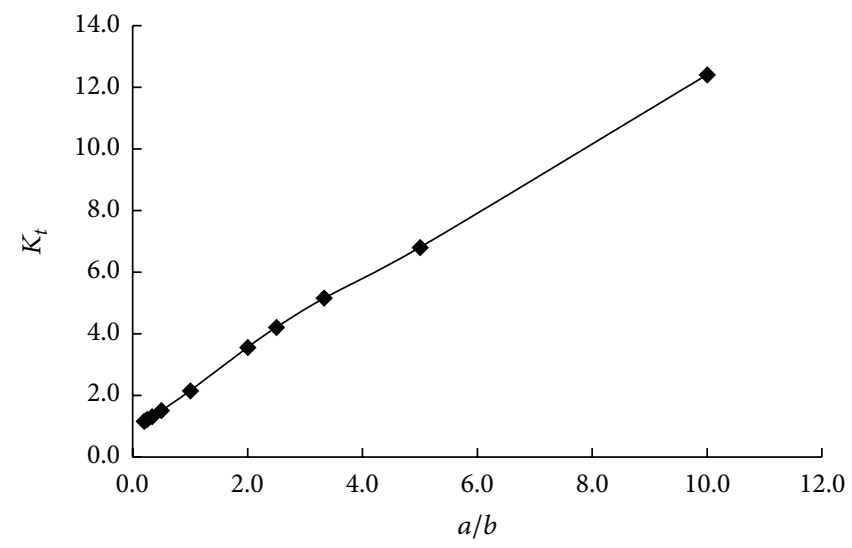

FIGURE 6: Variations of SCF with $a / b$ for $a=2 \mathrm{~mm}$.

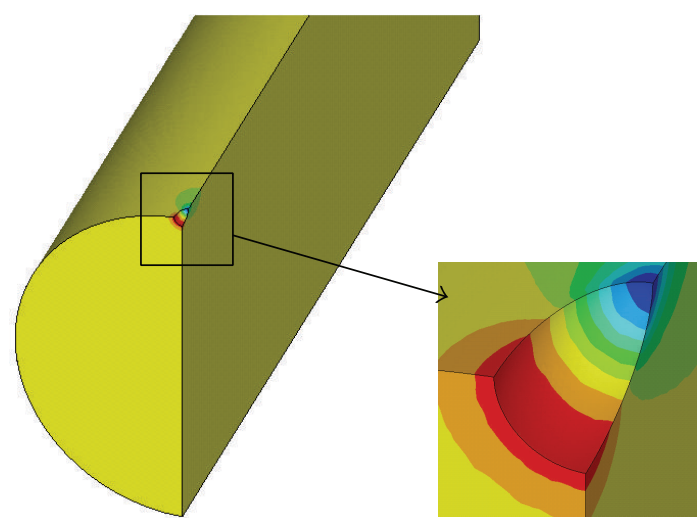

Min 0.9

$\operatorname{Max} 145.2$

(a)

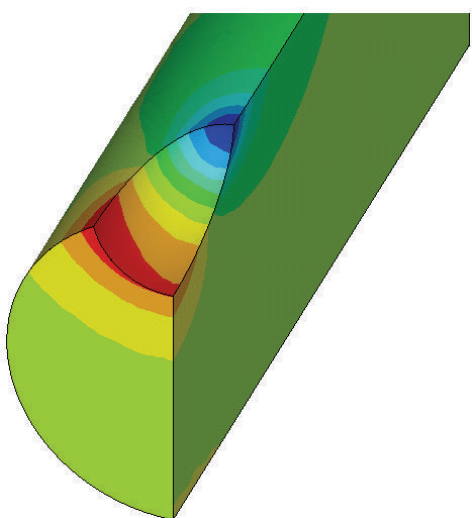

Min -1.3

$\operatorname{Max} 172.7$

(b)

FIGURE 7: Stress distributions near the pit with various relative depths: (a) $a / R=0.05$, (b) $a / R=0.5$.

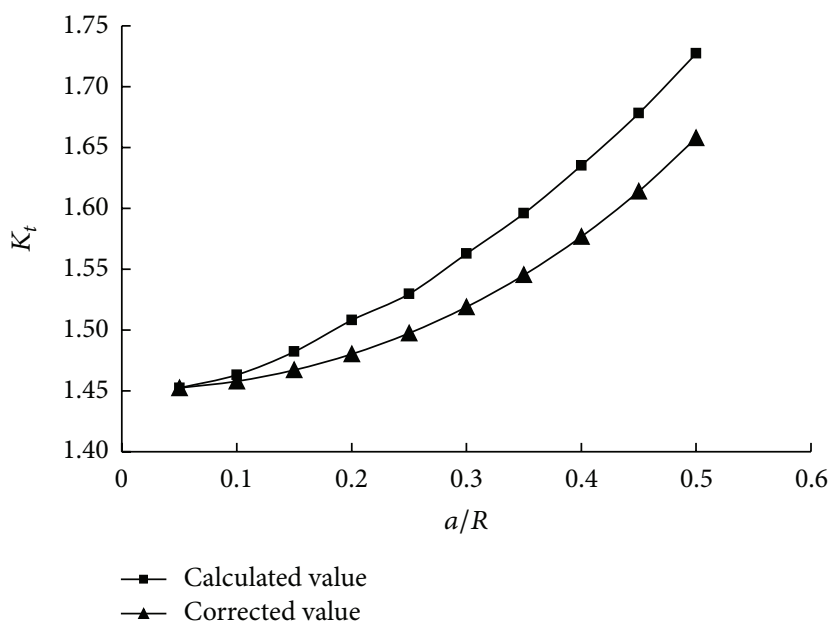

FIGURE 8: Variations of SCF with $a / R$ for $a / b=0.5$. 


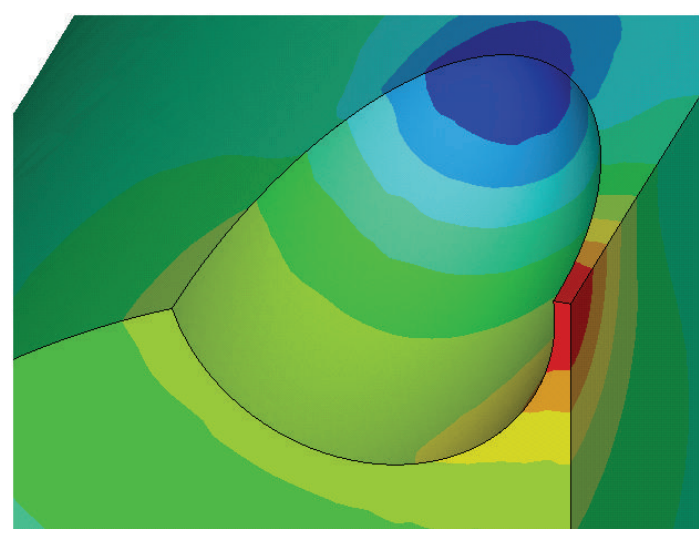

Min -1.3

Max 172.7

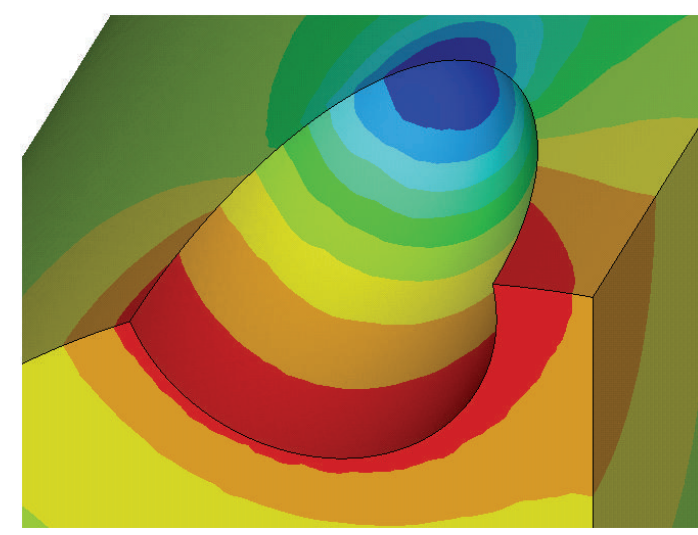

Min -1.1

Max 162.5

(a)

(b)

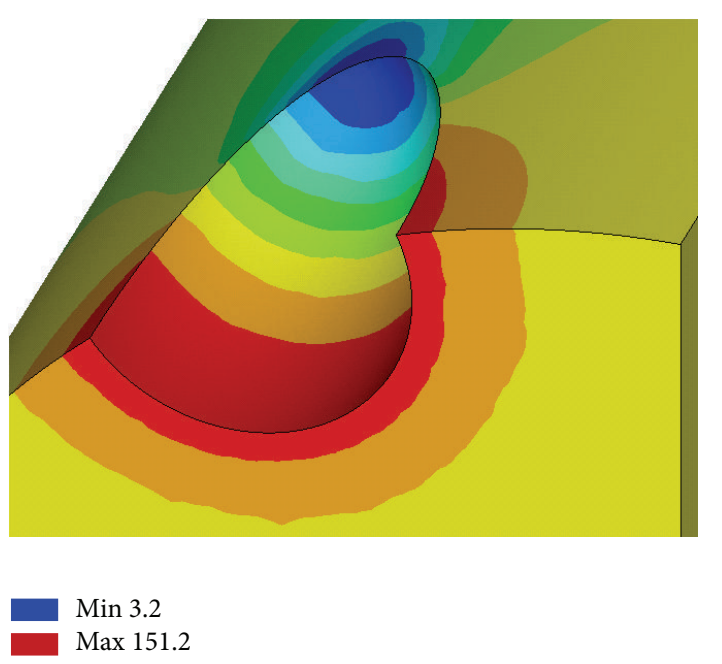

(c)

FIgURE 9: Stress distributions near the pit with various angles: (a) $\theta=25^{\circ}$, (b) $\theta=35^{\circ}$, and (c) $\theta=60^{\circ}$.

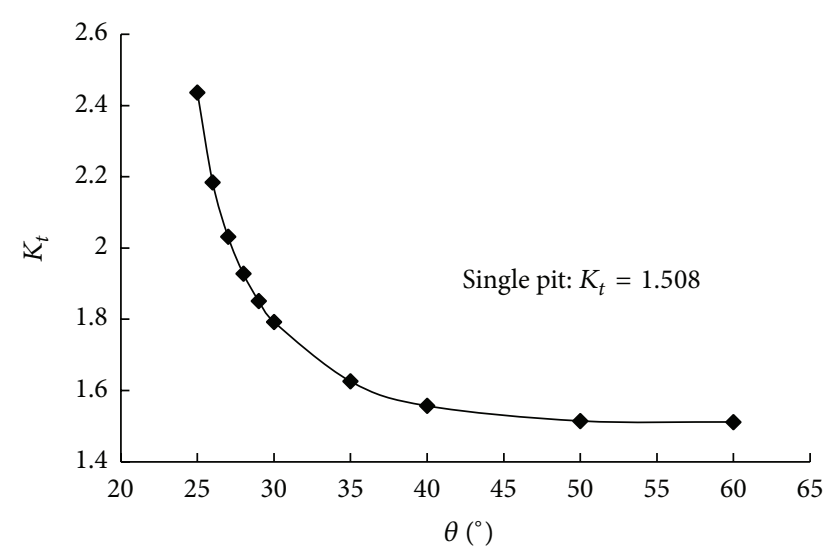

FIGURE 10: Variations of SCF with $\theta$ for $a=2 \mathrm{~mm}$ and $b=4 \mathrm{~mm}$.

the SCF values for two longitudinal pits' problem are even smaller than that for single pit problem. When $d=1 \mathrm{~mm}$ (given $a=2 \mathrm{~mm}$ and $b=4 \mathrm{~mm}$ ), the SCF value is 1.452 .
Consequently, the interaction of two longitudinal pits can be ignored in the calculation of SCF even if the distance of two pits is very small.

\section{Conclusions}

From this study, it is concluded that pit aspect ratio $(a / b)$ is a main parameter affecting the value of SCF. The SCF value increases linearly with increasing $a / b$ and increases nonlinearly with increasing pit relative depth $(a / R)$ for single corrosion pit problem. The maximum stress region is near the intermediate cross section of pit in tension direction and the maximum stress occurs at the cross points of the surface of steel bar and the intermediate cross section of pit.

For double corrosion pits problem, the SCF value decreases nonlinearly and approaches gradually that of single pit problem with increasing angle of two transverse pits $(\theta)$. When $\theta$ is small, the maximum stress occurs at the cross points near symmetry plane of the surface of steel bar and 


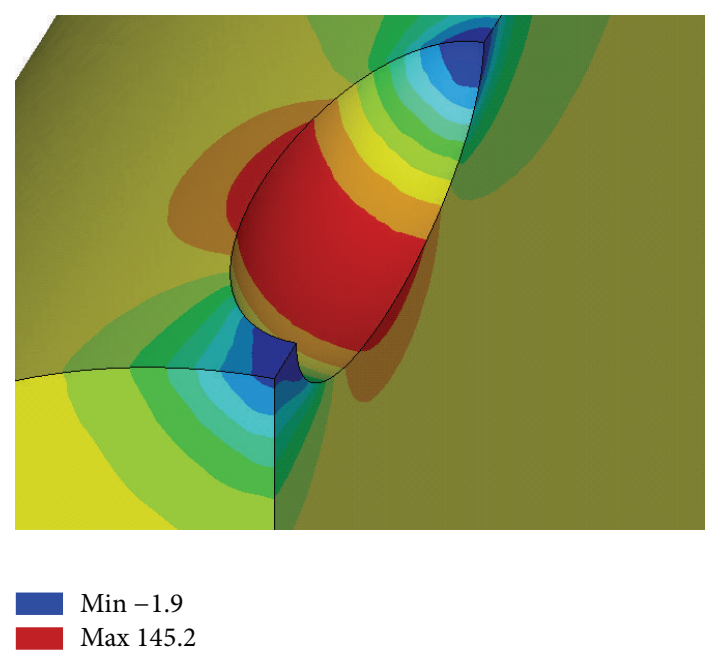

FIGURE 11: Stress distribution near the pit with $d=1 \mathrm{~mm}$.

the intermediate cross section of each pit. But when $\theta$ is big enough, the maximum stress occurs at the cross points away from symmetry plane of the surface of steel bar and the intermediate cross section of each pit. The interaction of two longitudinal pits can be ignored in the calculation of SCF even if the distance of two pits $(d)$ is very small.

\section{Conflict of Interests}

The authors declare that there is no conflict of interests regarding the publication of this paper.

\section{Acknowledgment}

This work was supported by the National Natural Science Foundation of China (Grants nos. 51208421 and 51378506).

\section{References}

[1] P. Ghods, O. B. Isgor, G. McRae, and T. Miller, "The effect of concrete pore solution composition on the quality of passive oxide films on black steel reinforcement," Cement and Concrete Composites, vol. 31, no. 1, pp. 2-11, 2009.

[2] X. Feng, Y. Zuo, Y. Tang, X. Zhao, and X. Lu, “The degradation of passive film on carbon steel in concrete pore solution under compressive and tensile stresses," Electrochimica Acta, vol. 58, no. 1, pp. 258-263, 2011.

[3] H. Yu, K.-T. K. Chiang, and L. Yang, “Threshold chloride level and characteristics of reinforcement corrosion initiation in simulated concrete pore solutions," Construction and Building Materials, vol. 26, no. 1, pp. 723-729, 2012.

[4] S. I. Rokhlin, J.-Y. Kim, H. Nagy, and B. Zoofan, "Effect of pitting corrosion on fatigue crack initiation and fatigue life," Engineering Fracture Mechanics, vol. 62, no. 4-5, pp. 425-444, 1999.

[5] P. S. Pao, S. J. Gill, and C. R. Feng, "On fatigue crack initiation from corrosion pits in 7075-T7351 aluminum alloy," Scripta Materialia, vol. 43, no. 5, pp. 391-396, 2000.
[6] T. Nakai, H. Matsushita, N. Yamamoto, and H. Arai, "Effect of pitting corrosion on local strength of hold frames of bulk carriers," Marine Structures, vol. 17, no. 5, pp. 403-432, 2004.

[7] R. François, I. Khan, and V. H. Dang, "Impact of corrosion on mechanical properties of steel embedded in 27-year-old corroded reinforced concrete beams," Materials and Structures, vol. 46, no. 6, pp. 899-910, 2013.

[8] Y. G. Du, L. A. Clark, and A. H. C. Chan, "Residual capacity of corroded reinforcing bars," Magazine of Concrete Research, vol. 57, no. 3, pp. 135-147, 2005.

[9] F. Tang, Z. Lin, G. Chen, and W. Yi, “Three-dimensional corrosion pit measurement and statistical mechanical degradation analysis of deformed steel bars subjected to accelerated corrosion," Construction and Building Materials, vol. 70, pp. 104-117, 2014.

[10] M. Cerit, "Numerical investigation on torsional stress concentration factor at the semi elliptical corrosion pit," Corrosion Science, vol. 67, pp. 225-232, 2013.

[11] Y. Huang, C. Wei, L. Chen, and P. Li, "Quantitative correlation between geometric parameters and stress concentration of corrosion pits," Engineering Failure Analysis, vol. 44, pp. 168178, 2014. 

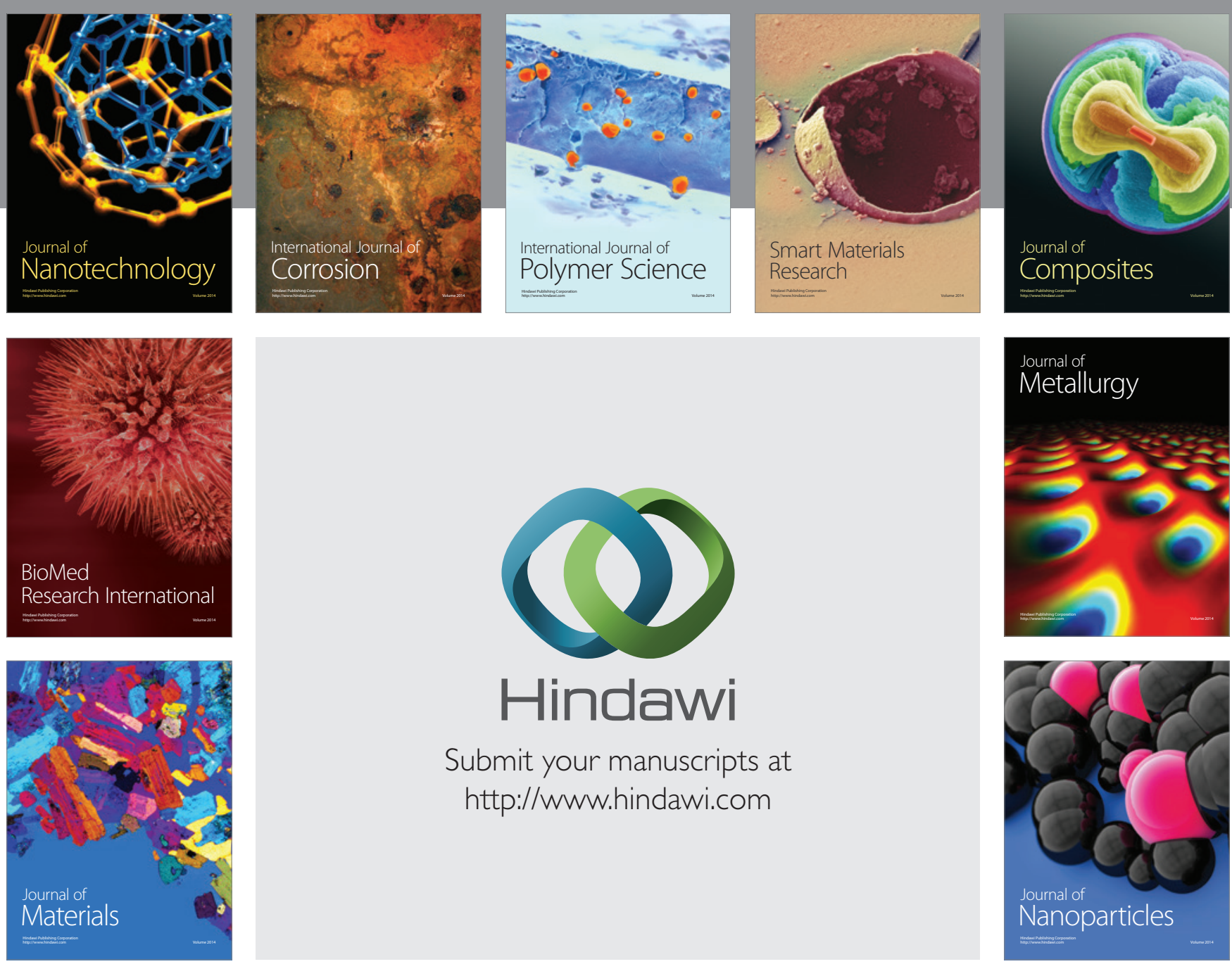

Submit your manuscripts at http://www.hindawi.com
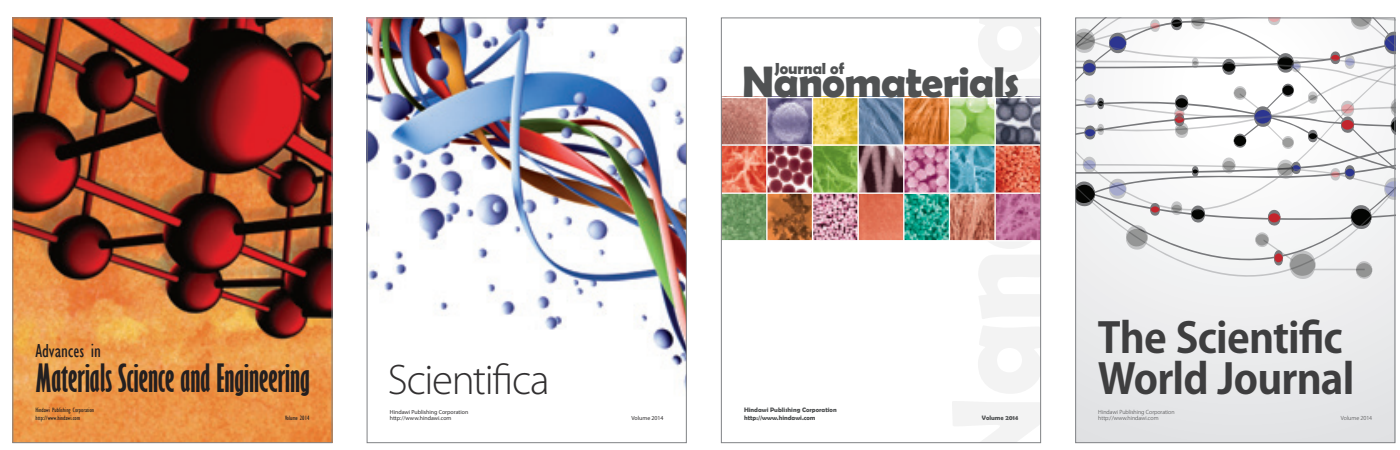

\section{The Scientific World Journal}
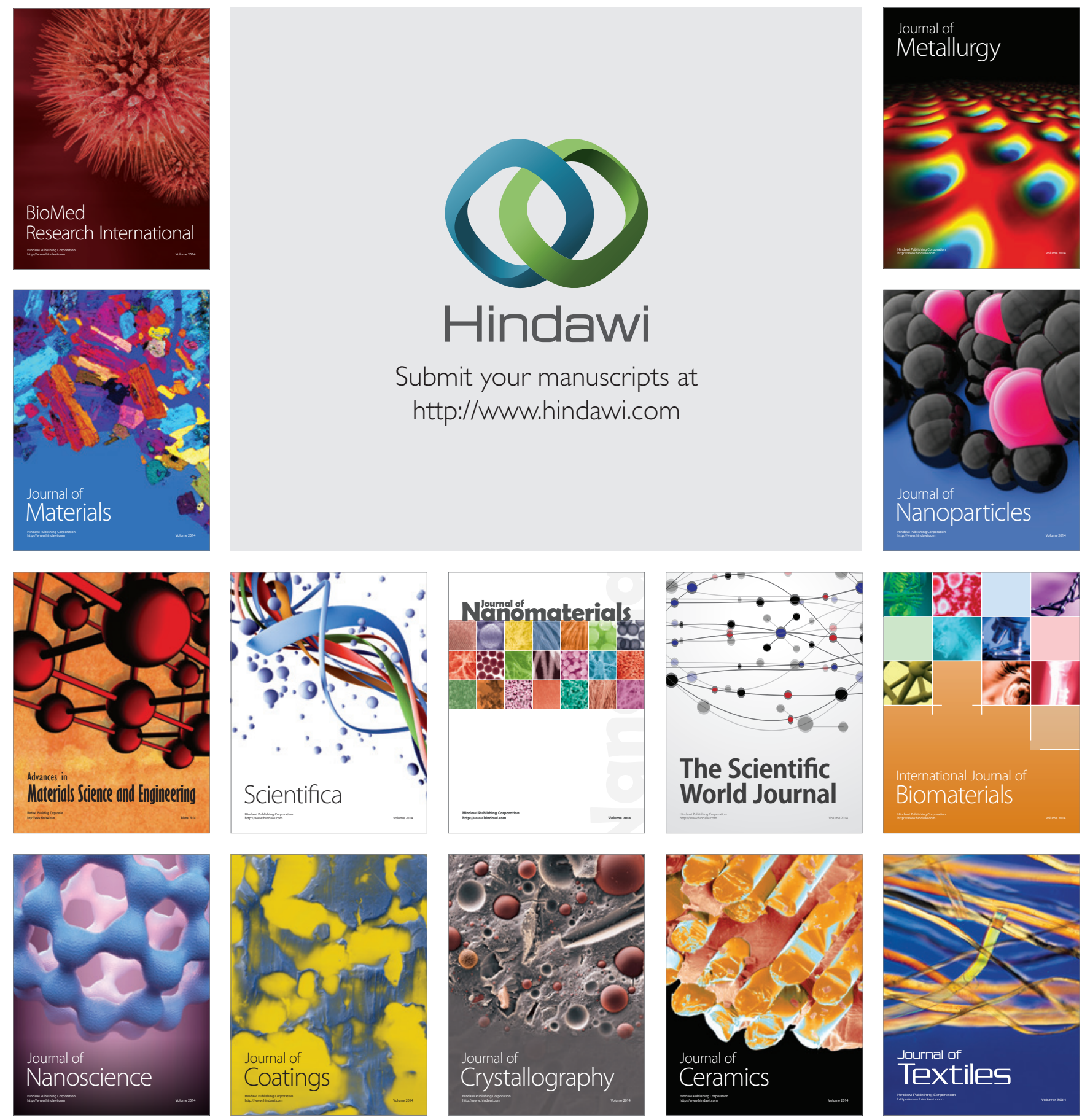